\title{
Dürer's diagnoses
}

The faces of the four apostles in Dürer's painting speak volumes about the saints' temperaments. This is no accident, as the artist was following the Renaissance medical theory of the four humours.

\section{Martin Kemp}

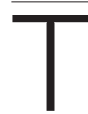
he great German painter, printmaker and theorist, Albrecht Dürer, shared with Leonardo da Vinci the quest for an art that would be 'universal' — one that constructs representations of all forms in nature on the basis of a profound understanding of natural philosophy in all its relevant facets. So, when portraying human beings, the mental and physical constitutions of each individual were to be expressed in terms of the Renaissance theories of psychology and physiology.

The medical basis for characterization was the ancient and persistent doctrine of the four humours - sanguine, phlegmatic, choleric and melancholic which were locked into the universal, four-fold scheme of the elements, times of day, seasons, winds and ages of man.

The constitution of those who exhibited the sanguine temperament was composed from the predominance of the humour of blood, and was of the nature of air, morning, spring, Zephyr and youth. The other equations were: phlegmatics with phlegm (inevitably), water, night, winter, Auster and old age; cholerics with yellow gall, fire, midday, summer, Eurus and maturity; and melancholics with black gall, earth, evening, autumn, Boreas and later middle age. Each temperament manifested itself not only in behaviour but also in physical characteristics and 'complexions', not least in physiognomy and the colour and texture of skin.

Dürer was fully conversant with such theories and embodied them in various prints, but their most complete expression is in the two magnificent panels of the Four Apostles that the ageing artist presented as his own 'memorial' to his home city of Nuremberg in 1526. Accompanied by Lutheran texts from the Bible, they testify in equal measure to Dürer's religious and intellectual allegiances.

The learned calligrapher, Johann Neudörffer, who wrote the inscriptions, recorded that each apostle embodied a specific temperament. There is the sanguine St John the Evangelist, ruddy in garment and complexion, the phlegmatic St Peter, bald and stolid, the leonine St Mark, choleric in character and physiognomy, and the sallow-skinned St Paul, who exhibits the haunted look associated with melancholy 'genius'. Like a doctor, expected to observe the external 'signs' of humoral imbalance, the spectator is presented with diagnostic clues through which Dürer invites us to discern the apostles' deepest natures in the context of the four-fold essence of God's creation.
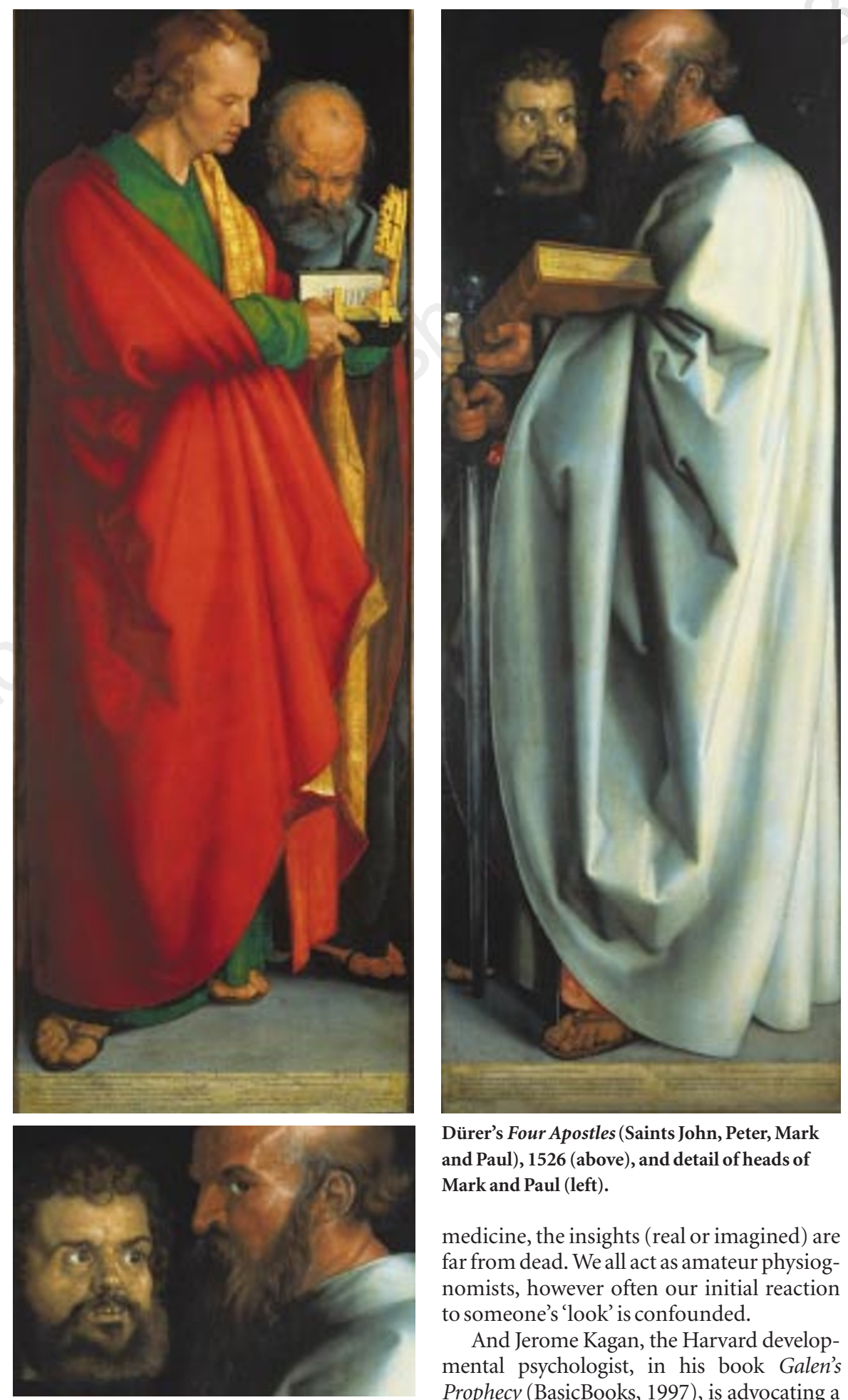

Dürer's manner of characterizing individual temperaments exercised a longlasting impact, not only on physiognomics but also on the nineteenth-century sciences of phrenology, craniology and eugenics. Even now, after the refutation of humoral
Dürer's Four Apostles (Saints John, Peter, Mark and Paul), 1526 (above), and detail of heads of Mark and Paul (left).

medicine, the insights (real or imagined) are far from dead. We all act as amateur physiognomists, however often our initial reaction to someone's 'look' is confounded.

And Jerome Kagan, the Harvard developmental psychologist, in his book Galen's Prophecy (BasicBooks, 1997), is advocating a return to four-part division of personality timid, bold, upbeat and melancholy - as corresponding to patterns of brain activity.

Martin Kemp is in the Department of the History of Art, University of Oxford, 35 Beaumont Street,

Oxford OX1 2PG, UK. 